\title{
Low back ache in working women of reproductive age group in an urban area
}

\author{
Nupur Nandi, Banasree Bhadra \\ Correspondence: Banasree Bhadra, Associate Professor, Department of Obstetrics and \\ Gynaecology, College of Medicine \& JNM Hospital Kalyani (Nadia), WB, India; Email - \\ banasree22@yahoo.com
}

Distributed under Creative Commons Attribution-Share Alike 4.0 International.

\begin{abstract}
$\underline{\text { ABSTRACT }}$
Background - Back pain is a common complaint and is acknowledged as an important socioeconomic and health problem. Low back ache (LBA) not only leads to poor quality of life for individuals all over the world but also leads to decreased productivity. Objective - This study was taken up with the aim to establish the prevalence of LBA in women of reproductive age group. In addition, correlation of LBA with overweight, reproductive factors, like age at marriage, marriage duration, past pregnancy, number of children or abortions, and posture during working were evaluated. Materials and Methods - It was one year prospective study on working women in reproductive age group (18-49 years) who presented in the out patient department of Obstetrics and Gynaecology. They were interviewed through questionnaire after obtaining an informed consent. Statistical analysis of data was done by proportions and tests of significance. Results - The prevalence of LBA was $57.7 \%$. The symptoms of LBA were more among women who were married after 30 years of age (62\%), had more $\geq 2$ deliveries $(60.6 \%)$ and had $\geq 2$ abortions (78.8\%). Prevalence of LBA was more among women with BMI $\geq 30$ and who worked in sitting posture for $>3$ hours. Conclusion - Prevalence of LBA in working women in reproductive age group is high. There is correlation between LBA and age at marriage, past pregnancy (including previous deliveries and abortions), obesity and posture while working. Thus attention must be paid to weight control, posture while working and time duration at work place.
\end{abstract}

Keywords: Low back ache, working women.

Back pain is a common complaint and is acknowledged as an important socioeconomic and health problem. Low back ache (LBA) not only leads to poor quality of life for individuals all over the world but also leads to decreased productivity due to time off work, increased absenteeism and early retirement. ${ }^{1}$ Physical, mental and emotional health gets affected by constant LBP.

LBA affects women more often than men and this leads to believe that the cause lies in female reproductive system. $^{2}$ The female muscular and ligamentary supports are not very strong in females. Further, during pregnancy and labor the mobility of the pelvic girdle exposes the muscles and ligaments to undue strains which after delivery involute suboptimally. A higher number of live births are suggested to be associated with LBA. ${ }^{3}$ During postpartum period women are exposed to additional physical work and have inadequate rest and sleep.

Received: $25^{\text {th }}$ March 2018. Accepted: $30^{\text {th }}$ June 2018.

Nandi N, Bhadra B. Low back ache in working women of reproductive age group in an urban area. The New Indian Journal of OBGYN. 2018; 5(1): 43-46. 
The etiology of back pain is multifactorial. LBA can be caused be gynaecologic, vascular, neurologic, psychogenic, spondylogenic or discogenic pathology. But mostly the cause remains unidentifiable and is encompassed under the umbrella term-mechanical or postural back pain. ${ }^{4}$ Minor repeated trauma is commonly accounted for by bending and lifting, obesity, pendulous abdomen, poor posture, flat feet, badly designed high heel shoes, long working hours etc. and are characterized by spasm of muscles. It is suggested that spasm may be the cause rather than the effect. Any LBA caused by gynecological lesion is diffuse, situated in midline and importantly associated with anterior pelvic pain. Any backache which can be pointed with a finger, or associated with local tenderness, is usually not due to intrapelvic lesion. ${ }^{5}$ Determination of the cause of LBA by detailed history taking, examination (including pelvic examination), radiological investigations is useful to plan treatment. But when definitive lesion is not found, reassurance, correction of posture, abdominal-spinal exercises, appropriate foot wear and adequate rest is recommended. ${ }^{2}$ This study was taken up with the aim to establish the prevalence of LBA in women of reproductive age group. In addition, correlation of LBA with overweight, reproductive factors, like age at marriage, marriage duration, past pregnancy, number of children or abortions, and posture during working were evaluated.

\section{Materials and Methods}

It was a prospective study conducted in Department of Obstetrics and Gynaecology at KPC Medical College, Kolkata, between Jan 2017 and December 2017. The study was approved by the Ethics Committee of KPC Medical College. One hundred thirty eight (138) working women in reproductive age group (18-49 years) who presented in the out patient department of Obstetrics and Gynaecology, were included in the study. Women having symptoms suggestive of reproductive tract infection (RTI) in the form of abnormal vaginal discharge, lower abdominal pain, urinary symptoms, vaginal pruritis, dyspareunia and suspected cases of sexually transmitted diseases (trichomonas vaginitis, gonorrhea, syphilis, candidiasis) were excluded from the study. Women using intrauterine contraceptive devices were also excluded.
The women were assessed by detailed history and clinical examination. They were interviewed through predesigned schedule after obtaining an informed consent. They were approached with covering letter outlining the purpose of the survey and brief questionnaire. The first part of it consisted of questions on age, height, weight, number of years in working and main posture (sitting, standing, bending, twisting or lifting weight) during working, medical history, sexual behavior, reproductive history and obstetrics history.

The second part consisted of questions related to LBA mainly its duration, occurrence in the past, location, radiation to legs, aggravating or relieving factors, any previous treatment/investigations required for it. Symptoms suggestive of reproductive tract infection (RTI) in past week or 6 months were recorded, depicting acute or chronic infection. Further questions consisted of need for orthopedic consultation and investigations (Xrays or MRI). Statistical analysis data obtained was collected and analyzed statistically by proportions and tests of significance. Statistical significance was set at $\mathrm{p}<$ 0.05 .

\section{Results}

Of the 138 patients analyzed, 123 patients returned with completed questionnaire hence, response rate was

Table 1: Distribution of cases according to symptoms of LBA

\begin{tabular}{lcc}
\hline Symptoms & Number of women & Percentage \\
\hline Without LBA & 52 & $42.3 \%$ \\
With LBA & 71 & $57.7 \%$ \\
\hline
\end{tabular}

Table 2: Distribution of $\mathrm{LBA}$ cases according to reproductive characteristics

\begin{tabular}{llcc}
\hline Categories & & Number (\%) & P value \\
\hline Age at & $<25$ & $22(31 \%)$ & 64.58 \\
marriage & $25-29$ & $5(7.04 \%)$ & $(<.0001)$ \\
(years) & Above 30 & $44(62 \%)$ & \\
\hline Marriage age & $<10$ & $19(26.7 \%)$ & 2.197 \\
(years) & $10-20$ & $27(38 \%)$ & $(0.333)$ \\
& $>20$ & $25(35.2 \%)$ & \\
\hline Number of & 0 & $4(5.6 \%)$ & 48.81 \\
deliveries & 1 & $24(33.8 \%)$ & $(<.0001)$ \\
& $\geq 2$ & $43(60.6 \%)$ & \\
\hline Number of & 0 & $6(8.4 \%)$ & 99.68 \\
Abortion & 1 & $9(12.6 \%)$ & $(<.0001)$ \\
& $\geq 2$ & $56(78.8 \%)$ & \\
\hline
\end{tabular}


$89 \%$. Out of the 123 working women in reproductive age group interviewed, 71 women $(57.7 \%$ ) had LBA as

Table 3: Distribution of LBA cases according to BMI and posture during work

\begin{tabular}{lllll}
\hline Variables & & $\begin{array}{l}\text { LBA } \\
\text { No (\%) }\end{array}$ & $\begin{array}{l}\text { No LBA } \\
\text { No (\%) }\end{array}$ & P value \\
\hline BMI & $\geq 30$ & $52(73.2 \%)$ & $24(46.1 \%)$ & 9.327 \\
& $20-29$ & $19(26.7 \%)$ & $28(53.8 \%)$ & $(0.002)$ \\
Position during working & Standing & $20(28.16 \%)$ & $26(50 \%)$ & 5.21 \\
(>3hours/day) & Sitting & $51(71.83 \%)$ & $26(50 \%)$ & $(0.022)$ \\
\hline
\end{tabular}

past and present complaints. The occupation of working women in reproductive age group presenting to us commonly were housemaids, teachers, nurses, computer operators, sales women and other desk jobs. All the women in our study group were married. Table 2 shows that the symptoms of LBA were more among women who were married after 30 years of age or had more $\geq 2$ deliveries or $\geq 2$ abortions. The relevant difference was statistically significant. From table 3 it is evident that the prevalence of LBA was more among women with BMI $\geq 30$ compared to women with BMI 20-29.

\section{Discussion}

Low back ache is a cause of sickness and disability in both developed and developing countries. In developing countries, the situation is reportedly worse with suboptimal working conditions, gross lack of awareness regarding education and training programs of LBP. ${ }^{6}$ In our study we observed that there was association of LBA with age at marriage, past pregnancy (including previous deliveries and abortions), obesity and posture while working. No positive association of LBA was observed with duration of marriage.

In our study $57.7 \%$ of women had LBA as past and present complaints which is similar to the findings of Dugan et al where $61 \%$ of women in the study group of 2218 reported lumbar spine pain. ${ }^{7}$ Another study by $\mathrm{S}$ Koms voll JF et al reported a 53\% prevalence of LBA in a group of working women while Dolan LM et al found the prevalence of LBA in gynaecologists to be $72 \%$.

It was found in our study that majority $(62 \%)$ of the cases of LBA had late marriage (after 30 years of age). Goel $\mathrm{S}$ et al also observed similar findings in their study. It is explained by the fact that late age may be a risk factor for musculoskeletal pains. Women having LBA in higher age group at marriage indirectly demonstrates that carrier oriented women marry late, thus predisposing to obstetric risks and increasing their chances of back pain. ${ }^{2}$

We observed that there is association of LBA with the number of deliveries and the number of abortions. In our study $60.6 \%$ of the cases with LBA had history of $\geq 2$ deliveries. This tallies with the population based survey by Silman AJ at al where linear association was found between the number of live births and chronic LBA. ${ }^{3}$ LBA was found in majority $(78.8 \%)$ of women with history of $\geq 2$ abortions in our study which is similar to the observations of Goel $\mathrm{S}$ et al. During pregnancy/abortion there is biomechanical stress on ligaments, muscle fatigue with effect of hormone relaxin on joint laxity. Thus past obstetric history is related with chronic LBA. Marnach ML et al postulated that high oestrogen level during pregnancy is responsible for this effect. $^{10}$

Szoeke et al noticed a direct association between increased BMI and increased spine pain. ${ }^{11} \mathrm{We}$ also found $73.2 \%$ of women with BMI $\geq 30$ had LBA. A three-year study by Brennan Braden et al examined 67,963 postmenopausal women aged 50-79 years with chronic pain and established that increased BMI $(\geq 30)$ was associated with the worsening of pain. ${ }^{12}$ According to Ratti $\mathrm{N}$ et al obesity is known to increase both the direct vertebra compressive load on the spine and the anteriorly acting loads which through the action of the muscles creates very large joint reaction forces. ${ }^{13}$

We observed that majority of cases with LBA gave history of more than 3 hours sitting at work place which is similar to another study by Shahzad S. ${ }^{1}$ Another research by Lewinnek GE et al states that severity of back pain was found associated with sitting for $>3$ hours. ${ }^{14}$ Dolan LM et al found that $54 \%$ of gynaecologists experienced back pain while performing surgery in sitting posture whereas $48 \%$ gynaecologists had back pain while performing surgery in standing posture. ${ }^{9}$ The reason explained for back pain in certain postures is due to generation of high stress concentrations on spinal segments. If posture is held for prolonged time some of the heavily loaded tissues creep gradually from load. ${ }^{15}$ 
The New Indian Journal of OBGYN. 2018 (July - December); 5(1)

\section{Conclusion}

Prevalence of LBA in working women in reproductive age group is high. There is correlation between LBA and age at marriage, past pregnancy (including previous deliveries and abortions), obesity and posture while working. Thus attention must be paid to weight control, posture while working and time duration at work place. Further research should be conducted to determine association between social factors and LBA so that proper strategies for the prevention of LBP in this age group can be planned and implemented.

\section{Conflict of interest: None. Disclaimer: Nil.}

\section{References}

1.Shahzad S. Social Determinants of Low Back Pain in Females of Reproductive Age Group Residing in Urban Lahore, Pakistan. Int Arch BioMed Clin Res. 2017; 3(4): 2023.

2.Goel S, Mani P, Mangla D, Goel JK. Low Back Ache in Working Women of Reproductive Age Group. J South Asian Feder Obst Gynae. 2015; 7(1): 33-6.

3.Silman AJ, Ferry S, Papageorgiou AC, et al. Number of children as a risk factor for low back pain in men and women. Arthritis Rheum I. 1995; 38:1232-35.

4.Chou R, Qaseem A, Snow V. Diagnosis and treatment of LBP: a joint clinical practice guideline from the American College of Physicians and the American Pain Society. Ann Intern Med. 2007; 147: 478.

5.Howard FM. Chronic Pelvic Pain. Obstet Gynecol. 2003; 101:594-611.

6.Sealetsa OJ, Tatcher A. Ergonomics issues among sewing machine operators in the textile manufacturing industry in Botswana. Work. 2011; 38(3): 279-89.
7.Dugan SA, Powell LH, Kravitz HM, et al. Musculoskeletal pain and menopausal status. Clin J Pain 2006; 22: 325-31.

8.Skoms voll JF, Ostensen M, Schei B. Reproduction in women reporting chronic musculoskeletal disorders. Scand I Rheumatol. 2000; 29:103-7.

9.Dolan LM, Martin DH. Backache in gynaecologists. Occup Med. 2001; 51: 433-38.

10.Marnach ML, Ramin KD, Ramsey PS, et al. Characterization of the relationship between joint laxity and maternal hormones in pregnancy. Obstet Gynecol. 2003;101: 331-35.

11.Szoeke CE, Cicuttini FM, Guthrie JR, Dennerstein L. The relationship of reports of aches and joint pains to the menopausal transition: a longitudinal study. Climacteric. 2008; 11: 55-62.

12.Brennan Braden J, Young A, Sullivan MD, et al. Predictors of change in pain and physical functioning among post-menopausal women with recurrent pain conditions in the Women's Health Initiative Observational Cohort. Pain. 2012; 13: 64-72.

13.Ratti N, Pilling K. Back pain in the workplace. Br J Rheumatol. 1997; 36: 260-64.

14.Lewinnek GE, Warfield CA. Facet joint degeneration as a cause of low back pain. Clinorthop. 1986; 213: 216-22.

15.Adams MA, Bogduk N, Burton K, Dolan P. Posture, creep and functional pathology. The Biomechanics of Back Pain, 3rd ed. New Delhi: Elsevier Publishers; 2013. p. 17388.

Nupur Nandi ${ }^{1}$, Banasree Bhadra ${ }^{2}$

${ }^{1}$ Associate Professor, Department of Obstetrics \& Gynaecology, KPC Medical College, Kolkata (WB) India; ${ }^{2}$ Associate Professor, Department of Obstetrics \& Gynaecology, College of Medicine \& JNM Hospital Kalyani (Nadia), WB, India. 